\title{
El objeto imantado y el espacio público. Praxis político-religiosa del movimiento Misioneros de Francisco en Argentina
}

\section{The magnetised object and the public space. Political- religious praxis in the Missionary's of Francis movement in Argentina}

\author{
Marcos Andrés Carbonelli* \\ * Centro de Estudios e Investigaciones Laborales / Consejo Nacional de \\ Investigaciones Científicas y Técnicas - Buenos Aires, Argentina \\ m_a.carbonelli@yahoo.com.ar \\ Verónica Giménez Béliveau ${ }^{* \star}$ \\ ${ }^{\star \star}$ Centro de Estudios e Investigaciones Laborales / Consejo Nacional de \\ Investigaciones Científicas y Técnicas - Buenos Aires, Argentina \\ veronicagimenezb@gmail.com
}




\title{
Resumen
}

Como un objeto imantado, el pontificado de Francisco atrajo las miradas y los intereses de actores políticos, religiosos, medios de comunicación y científicos sociales. Uno de los resultados de este efecto gravitacional fue la producción de nuevas formas de militancia política religiosa, en la que se destaca el movimiento Misioneros de Francisco, en Argentina. Desde una perspectiva etnográfica en este trabajo analizaremos la acción pública de este grupo en tres espacios diferentes- las plazas, la calle y el barrio-, para delinear la especificidad de su propuesta y sus niveles de eficacia en la difusión, de cara a las gramáticas territoriales y sus condicionantes. En las conclusiones las potencialidades y los límites del despliegue del movimiento en el espacio público, y sobre la importancia de la dimensión territorial en la proyección de las religiones contemporáneas.

Palabras clave: religión; política; espacio público; catolicismo.

\begin{abstract}
This article aims at analyse the actions in the public space of social movements based on a dynamic relation between politics and religion. The election of catholic Pope Francis gave birth to new ways of political and religious activism, that we focalise in the Movement 'Misioneros de Francisco' (Francis' Missionaries'). From an ethnographic perspective, this article identifies three privileged ways of being in the public space: the activism in the square, in the neighbourhood and in the street, and studies the ways of action and the disputes and issues towards the political and ecclesiastical institutions presents in the territory.
\end{abstract}

Keywords: religion, politics, public space, Catholicism. 


\section{Introducción}

En América Latina las manifestaciones religiosas han habitado históricamente el espacio público. Desde la constitución de los estados nacionales a finales del siglo XIX, y en paralelo con los procesos de reconfiguración de las relaciones entre instituciones estatales y eclesiásticas, la presencia de lo religioso ha poblado calles y plazas, ha atravesado movimientos políticos del orden y de la revuelta, ha simbolizado manifestaciones culturales y ha marcado los cuerpos de los creyentes.

La presencia de lo religioso en la escena pública contemporánea incomoda sin embargo a las Ciencias Sociales: ciertas formulaciones de la sociología y la ciencia política lo consideraban casi una anomalía, y la antropología exotizaba sus objetos ubicándolos fuera de los espacios definidos como modernos. Las Ciencias Sociales, hijas de la modernidad al fin, y de sus promesas de progreso indefinido y de acabar con el oscurantismo asociado a las creencias religiosas, miraba de costado las permanencia y aparición de manifestaciones religiosas en el espacio público.

Podríamos listar las corrientes de las Ciencias Sociales que han pensado el cruce religión y espacio púbico a partir de distintas entradas. Una primera entrada considera las relaciones entre política y religión a nivel institucional: los acuerdos políticos entre el estado y las iglesias, los alcances de los procesos de laicización (ver para el caso mexicano Blancarte, 2001, 2008, para el uruguayo Da Costa, 2009, para el brasilero Oro, 2011, para el argentino Esquivel, 2009 entre otros), las relaciones jurídicas entre el estado y las iglesias (Esquivel, 2013a), y las relaciones entre los grupos religiosos y los poderes políticos (Freston, 1994; Mallimaci, 2012; Oro, 2003).

La acción política de los agentes religiosos -individuos y colectivos- podría pensarse como otra entrada. Los estudios sobre la acción social de los grupos evangélicos (Fediakova 2012), la agencias políticas de los grupos religiosos en contextos territoriales específicos (Carbonelli, 2014, Giménez Béliveau, 2016), las intervenciones políticas de las instituciones y grupos religiosos (Carbonelli; Mosqueira; Felliti, 2011; Jones; Vaggione, 2013; Machado et al., 2006; Tadvald, 2015) muestran una agencia religiosa que reclama espacios de participación y exposición pública, y cuya intervención no está exenta de conflictos y tensiones.

Las investigaciones sobre fiestas y procesiones han mostrado una presencia continua y a la vez cambiante de lo religioso que se expresa en el territorio. 
Maues (2013) identifica distintos modelos de las peregrinaciones católica: la que se organiza alrededor de la Madre, y la que se centra en la figura del Hijo. En ambas encuentra combinados aspectos lúdicos con devoción y sufrimiento. En Argentina Ameigeiras (2008) ha estudiado la fiesta y peregrinación de Nuestro Señor de Mailín, en Santiago del Estero, y Flores (2013), Carballo (2010), Ceva (2013) y Touris (2013) han analizado las peregrinaciones marianas contemporáneas más masivas: la Virgen de Luján y la Virgen de San Nicolás. Estas dos fiestas, en sus distintos desarrollos, expresan con texturas diferenciadas las potencialidades protestatarias y las politicidad latente de las manifestaciones religiosas masivas.

Un interesante filón en el análisis contemporáneo de la presencia religiosa en fiestas y calles se relaciona con el consumo de objetos rituales y símbolos religiosos, y el desarrollo de emprendimientos turístico-religiosos. Estos circuitos simbólico-comerciales se caracterizan por la superposición de objetos y tradiciones culturales, como analiza Gutiérrez Zuñiga (2008, p. 379) a través de la presencia de prácticas y disciplinas de la danza neo-tradicional entre la oferta espiritual alternativa en Guadalajara, México, y enfatizan las relaciones entre espacios de interacción y formas de sociabilidad en la creación de circuitos de circulación de personas y objetos (Algranti, 2014). El turismo de masas como objeto de deseo de las sociedades contemporáneas también atraviesa las creencias y religiones, dando origen a interesantes articulaciones entre movilidades, motivaciones religiosas y espirituales y símbolos tomados de las tradiciones, releídos y transformados. Es el tema que abordan Zapponi (2008, 2011), Steil y Marques (2011) y Carneiro (2011) en sus estudios sobre las peregrinaciones contemporáneas en Europa y América Latina.

Otra entrada posible para pensar la presencia religiosa en el espacio público son los estudios que dan cuenta de las distintas presencias religiosas en el territorio, desde santuarios, templos y parroquias hasta altares, graffittis y marcas en calles, casas y edificios. Gutiérrez Zúñiga, De la Torre y Castro (2011) trabajan en la cartografía religiosa de la ciudad de Guadalajara, analizando la diversificación religiosa como proceso histórico, la distribución de los lugares de culto y las zonas de influencia de las distintas confesiones. Giménez Béliveau, Martínez (2013) y equipo analizan las marcas religiosas en el espacio público en cuatro ciudades en Argentina, destacando las formas de texturizar el espacio como apuesta indentitaria de grupos y colectivos religiosos. Suárez (2012) 
da cuenta de este espacio suburbano marcado religiosamente en un territorio periférico de la Ciudad de México. Cristos, altares y estatuas de vírgenes pueblan el tramado urbano, tensionando la relación entre confesiones religiosas y estado, y mostrando distintas modalidades de articulación entre religión y política (Giumbelli, 2014).

En el presente artículo nos interesa discutir el cruce entre religión y espacio público en las sociedades latinoamericanas contemporáneas a partir de un trabajo etnográfico llevado a cabo con un grupo que se sitúa en el cruce entre lo religioso y lo político, los Misioneros de Francisco. Nos preguntamos sobre las distintas formas de concebir y habitar el espacio público, a través de los proyectos políticos que actúan en el territorio, a la vez marcándolo y definiéndolo, y siendo construidos por las particularidades de éste.

Llegamos a nuestro tema de investigación como consecuencia de una emergencia del campo: la elección de Jorge Bergoglio como el primer papa latinoamericano nos llevó a intensificar la etnografía en los espacios públicos: hecho, inédito en la Iglesia, nos permitía suponer que sectores del catolicismo se movilizarían en nuestro territorio de análisis, la sociedad argentina contemporánea, y esto tendría su expresión en el espacio público concebido de distintas formas. No nos equivocamos en ese punto: en el momento de la elección y la posterior asunción de Francisco se realizaron manifestaciones frente a la catedral que reunieron gran cantidad de público: vigilias, procesiones, actos. Los grupos juveniles y parroquiales católicos aparecieron como los sectores más movilizados (Giménez Béliveau, 2013). Esa efervescencia, mezcla de orgullo nacional y renovado fervor religioso de grupos de activistas, tuvo consecuencias inesperadas: el reacalentamiento del lazo entre religión y política en grupos -minoritarios pero influyentes- que, estrechando los lazos preexistentes entre catolicismo y peronismo, propusieron nuevas formas de militancias en el cruce entre lo religioso y lo político. Así nació Misioneros de Francisco, ${ }^{1}$ el grupo sobre cuyo análisis está basado este artículo, y así tuvo origen también una investigación que surgió preguntándose por las modalidades en que se manifiestan en el espacio público los lazos entre religión y política desde las bases, en tiempos de un papa latinoamericano.

1 Misioneros de Francisco no es el único grupo que surge en la intersección del catolicismo y el peronismo en ese período, aunque sí es uno de los que reúne más militantes. 
Comenzamos a seguir a los Misioneros de Francisco en 2014, a través de las técnicas del trabajo etnográfico. Durante más de tres años asistimos a reuniones, viajes, peregrinaciones; visitamos capillas y participamos de rituales religiosos, conversamos con los miembros de Misioneros. Realizamos entrevistas, registramos los encuentros en diarios y notas de campo, y tomamos fotografías.

El grupo y sus acciones en el territorio trascendieron relativamente rápido a la esfera mediática: en agosto de 2014, una crónica del diario La Nación (uno de los diarios de mayor tirada en Argentina) titula "Misioneros de Francisco: capillas en las villas donde conviven política y religión" (Sued, 2014). La nota da cuenta del fenómeno emergente, y habla del grupo cuya intención es la combinación de prácticas políticas y religiosas en pos de la activación y recuperación de la devoción y la politicidad popular.

El crecimiento del grupo y su trascendencia en la escena pública alentaron la investigación que hoy lleva tres años y que en sus inicios giró en torno de los siguientes interrogantes ¿Cuáles eran las razones de una experiencia mixta como la de las capillas de Misioneros de Francisco? ¿Por qué convergían en este proyecto agencias políticas y religiosas dispares y desencontradas en el contexto previo? ¿Qué objetivos perseguían cada uno de sus participantes? ¿Se trataba del ejercicio de un catolicismo por otros medios en pos de recuperar terreno perdido (en manos pentecostales, cfr. Semán, 2000) en el campo popular? ¿O se trataba de un uso estratégico del sello y la figura del pontífice en particular y del catolicismo en general con el objetivo de profundizar el anclaje territorial de la militancia peronista? ¿Estaríamos frente a un fenómeno que trascendía las racionalidades estratégicas y de manera genuina significaría una (nueva) fusión entre catolicismo y peronismo?

Para comprender la urdimbre de sentidos constitutiva del movimiento contactamos y logramos entrevistar a algunos de los referentes del espacio. De ellos obtuvimos dos elementos que se volvieron indispensables para el despliegue de nuestra investigación. En primer lugar, la narrativa del mito fundante de Misioneros de Francisco, donde se alude al momento en el que Emilio Pérsico, dirigente del Movimiento Evita, ${ }^{2}$ se entrevista en 2014 con Francisco

2 El Movimiento Evita es una agrupación de la galaxia peronista- kirchnerista, que se caracteriza por su trabajo territorial, su interés en la organización de los trabajadores informales, y su "vocación movimientista, con predominio de una estrategia heterónoma e impronta plebiscitaria de $\rightarrow$ 
en su residencia en Santa Marta, conversan distendidos sobre la realidad sociopolítica Argentina, y como balance de sus diagnósticos y preocupaciones comunes aflora una sugerencia pontificia: "ponete a hacer capillas en los barrios". ${ }^{3}$ En segundo término, la legitimidad para continuar nuestras indagaciones sobre la experiencia Misioneros de Francisco en terreno, a partir de un seguimiento de sus acciones en el espacio público. En otras palabras, los dirigentes nos habilitaron lo que en investigaciones cualitativas en ciencias sociales se conoce como "el ingreso al campo".

La historia de Misioneros está marcada por la doble tradición de una Iglesia "en salida", pregonada por el Papa Francisco, y del peronismo que va hacia "el pueblo". El espacio público como esfera de acción privilegiada está en el origen de este doble movimiento: este será el tema de nuestro primer apartado. En el segundo apartado trabajaremos una de las formas de habitar el espacio público, la construcción de capillas. En el tercer apartado analizaremos otra de las modalidades privilegiadas por Misioneros, las peregrinaciones y manifestaciones en el espacio urbano. El tránsito y la permanencia en el espacio público del Movimiento tensiona los lazos con las instituciones y los agentes que marcan su doble adscripción, entre la religión y la política: la Iglesia católica, y los agentes partidarios y estatales en sus distintos niveles. En las conclusiones reflexionaremos sobre el despliegue del movimiento como propuesta de construcción de nuevas territorialidades.

\section{La materialización del “hagan lío”: de Francisco a las calles}

La elección del cardenal Argentino Jorge Bergoglio como sumo pontífice el 13 de marzo de 2013 constituyó un evento central para actores políticos, religiosos y científicos sociales. A escala global se procuró descifrar las razones de la elección de un papa latinoamericano en el contexto de una Iglesia

$\rightarrow$ legitimación de acciones y decisiones políticas" (Natalucci, 2012, p. 28). Nace a partir de 2003, en el momento en que diversos grupos políticos de origen peronista y piquetero fundan el movimiento político.

3 Relato del sacerdote Eduardo Farrell, fundador de Misioneros, entrevista del 13/04/2015, Buenos Aires. 
en crisis, que todavía procesaba la excepcional renuncia de Benedicto XVI, y el agotamiento de un modelo eclesial que revelaba una problemática relación con la modernidad, la pérdida de fieles y la burocratización excesiva de la institución con escándalos económicos y sexuales incluidos (Ameigeiras, 2013a). En el plano local, el impacto se multiplicó a partir del efecto de la proximidad: el cardenal era una figura notable de la vida político y religiosa en Argentina, conocido por sus tensiones con el gobierno kirchnerista (Mallimaci, 2012) y por su filiación a un modelo católico que reivindicaba las devociones y las organizaciones del pueblo.

Así, en el subcampo de las relaciones político-religiosas, las acciones cobraron notoriedad y se activó lo que Esquivel (2013b) ha denominado "la carrera por el papa propio": la búsqueda de las agencias políticas por apropiarse del mensaje y la figura de sumo pontífice, y extraer de esta proximidad un plus de legitimidad para el juego político. Este supuesto es uno de los patrones de conducta más estudiados por los especialistas en la materia y es lo que ha llevado a pensar en el espacio político religioso como un espacio integrado, continuo (Mallimaci; Esquivel, 2011), en el que los capitales, los actores, los discursos y las utopías de un campo pueden trasvasarse hacia el otro y viceversa.

Las ciencias sociales tampoco permanecieron ajenas a esta movilización. Hasta el momento en el estado de la cuestión se contabilizan libros (Frigerio; Renold, 2015; Prieto, 2016), dossiers de revistas (Sociedad y Religión, 2013) y artículos producidos por especialistas, donde se trazan las primeras conjeturas descriptivas y explicativas sobre la figura de Francisco (Giménez Béliveau, 2015; Mallimaci, 2013a, 2013b) y las consecuencias de sus acciones para el catolicismo en particular y para el campo religioso en general. En términos metafóricos pueden pensarse la emergencia del papado latinoamericano como un nuevo y curioso astro en el universo de los fenómenos conocidos, cuyo campo gravitacional de interés atrae a actores políticos, religiosos y científicos. Francisco resulta un objeto imantado.

Nos dejamos arrastrar por esta fuerza de atracción y realizamos una primera cobertura etnográfica sobre las movilizaciones que el nombramiento de Francisco suscitaba en la ciudad de Buenos Aires. Se organizó una vigilia celebratoria, donde se confundían las organizaciones católicas, personalidades eclesiásticas, funcionarios y dirigentes políticos de extracción diversa. Entre estos últimos nos llamó la atención la presencia de Emilio Pérsico, referente 
del Movimiento Evita, una de las organizaciones de militancia peronista de base más importantes en el ciclo militante que se reinauguró en 2001 (Natalucci, 2012). Nuestra perplejidad hundía raíces en las tensiones entre los sucesivos gobiernos kirchneristas, la fuerza política en la cual Pérsico se inscribía, y el reciente Papa cuando era arzobispo de Buenos Aires. Interpretamos esa aparición en primera instancia como una conducta habitual que estructura las pautas de acción entre las agencias políticas y religiosas en torno a la transferencia reciproca de legitimidades, más allá de las tensiones coyunturales.

Nuestros primeros análisis etnográficos se cernieron en torno a las actividades que el Movimiento comenzaba a emprender en plaza Constitución y plaza Moreno. Ambos espacios fueron conceptualizados desde nuestra mirada analítica como arenas públicas en términos de Cefaï (2002), esto es, espacios públicos donde diferentes actores socio-políticos ensayan argumentos, emprenden acciones proselitistas, sellan alianzas, procuran dejar marcas en el espacio y su densidad simbólica. También este autor nos advierte que dichos espacios expresan una gramática propia, esto es, un conjunto de reglas explicitas e implícitas que enmarcan las iniciativas posibles en dichos espacios, delineando sus horizontes de posibilidad y sus límites. Si nos ceñimos entonces a las características públicas de estos espacios de y para la acción, se destaca la circulación como elemento distintivo. Plaza Constitución es una de las terminales de trenes más importantes que conecta a la ciudad de Buenos Aires con su periferia sur. Por día circulan en su explanada un millar de personas que se acercan a la metrópoli para trabajar, para realizar trámites, para estudiar, para atenderse en un centro de salud. En términos de logística urbana, Plaza Moreno - uno de los centros del conurbano oeste- responde a coordenadas similares: representa la principal terminal de confluencia de personas y transportes, con la salvedad que, por su ubicación geográfica, por ella transitan fundamentalmente trabajadores de los sectores populares.

Además del gran marco de visibilidad que ofrecían las plazas, con el tiempo descubrimos que la elección de estos centros urbanos también respondía a criterios políticos. Plaza Constitución y Plaza Moreno constituían territorios "amigos": el primero es muy cercano a la sede Central de la Conferencia de Trabajadores de la Economía Popular (CTEP), organización que nuclea a su tiempo a varios movimientos sociales donde militan simultáneamente no pocos miembros de Misioneros de Francisco y que constituye el lugar donde 
éstos tienen sus reuniones mensuales. Plaza Constitución es además un lugar atravesado sistemáticamente por acciones políticas y religiosas: los días miércoles predican los fieles de la cercana Parroquia Santa Elisa, todos los días los Testigos de Jehová instalan un stand con folletería, el Partido Obrero se hace presente varias veces por semana para repartir volantes. Por su parte Plaza Moreno se encuentra dentro de la diócesis de Merlo Moreno, una de las pocas jurisdicciones católicas que permitió y alentó las actividades religiosas de los Misioneros: el padre Eduardo Farrell, uno de los fundadores de Misioneros, está incardinado en la diócesis, y manifiesta profundas coincidencias pastorales con el obispo.

El despliegue del accionar misionero en estos espacios observó un guión común. Los Misioneros de Francisco dispusieron una imagen de la virgen de Lujan en el centro del hall de Plaza Constitución y se colocaron en sus inmediaciones, con estampitas del Papa Francisco o de la Virgen de Luján que repartían entre los transeúntes. También los invitaban a ser bendecidos por el sacerdote que se encontraba al costado de la imagen o para dejar sus intenciones en un papel escrito a los pies de la Virgen. La actividad era anunciada por un megáfono, que alternaba con canciones parroquiales y rezos colectivos. En sus intervenciones, los Misioneros no se presentaban como grupo: su trabajo estaba concentrado en propiciar entre las multitudes un espacio de recogimiento, de súplica y de bendición. En esta dinámica, muchas personas hacían fila para ser bendecidos por el cura y tocar la imagen de la Virgen (que estaba estratégicamente dispuesta en un punto de conexión entre la salida ferroviaria y las escaleras que conducen a la estación de subterráneos), que se ganaba la atención de la mayoría. La actividad en su totalidad duró aproximadamente una hora y culminó con una oración comunitaria donde los Misioneros agradecieron a Dios la posibilidad de haber dado a conocer su presencia y pidieron por el crecimiento del Movimiento y sus actividades.

Para comprender estas actividades iniciáticas resultó fundamental no sólo observar la actividad pública, sino también estar presentes en las reuniones evaluatorias. Allí los Misioneros hicieron una puesta en común y compartieron sus impresiones de lo vivido. Destacaron la buena recepción de las personas a sus invitaciones, la manera en que las personas se habían "enganchado" con las oraciones comunitarias y con el contacto físico con la imagen de la virgen. En el relato de no pocos apareció la novedad de la experiencia: para la mayoría 
era la primera vez que participan de actividades de este tipo y se maravillaban de la religiosidad presente en personas desconocidas. Este asombro expresado intersubjetivamente nos permitió perfilar la composición de los cuadros de MMF: muchos de sus miembros no provenían de sociabilidades parroquiales, sino del mundo de la militancia peronista en su versión kirchnerista. Misioneros se constituía así, desde sus orígenes, en un grupo donde convivían legos y expertos (Berger; Luckmann, 1989) en la tarea de la difusión de un mensaje religioso. También en dicho espacio reducido entendimos que la elección de lugares como Plaza Constitución o Plaza Moreno respondía a la búsqueda de un contacto con un sujeto que era construido comunitariamente como el destinatario preferencial del mensaje religioso, el "pueblo trabajador", el "pueblo pobre", el "pueblo católico". Este objetivo, profesado por sus organizadores en la reunión de evaluación, ligaba a Misioneros de Francisco con una tradición pastoral y teológica particular: la teología del Pueblo, una variante teológica elaborada por un grupo de sacerdotes postconciliares en la Argentina para la cual el contacto con lo sagrado no descansa en la mediación burocrática, sino en las prácticas y creencias populares ${ }^{4}$ (Ameigeiras, 2013b). Cabe destacar que si bien esta perspectiva expresa evidentes preocupaciones espirituales, no constituye una cosmovisión despolitizada: en su planteo, rescatar las creencias del Pueblo también incluye acompañarlo en sus luchas y demandas.

En el registro de estas actividades y de su evaluación también detectamos la importancia de los objetos en tanto marcadores territoriales, íconos capaces de construir fronteras y comunidades, y alterar, aunque sea por unas horas, la dinámica anónima del paso multitudinario y construir una geografía propia, un territorio "santo". La agencia de las vírgenes se constituyó tempranamente en nuestro abordaje etnográfico una trama rastreable, multisituada (Marcus, 1995). Si en el caso de las misiones en Plaza Constitución y Moreno, las vírgenes favorecieron el bautismo proselitista de los Misioneros y sus primeros contactos con su público destinatario, más tarde cobraron relevancia marcada como formas de acceso al contacto con el líder por antonomasia del movimiento,

4 Se conoce como "Teología del Pueblo" al movimiento teológico-pastoral cuyas figuras centrales fueron Rafael Tello y Lucio Gera. Esta corriente define al sujeto histórico de la fe como "pueblo de Dios", y destaca la cultura mestiza, las raíces latinoamericanas, la evangelización y la espiritualidad mariana (Ameigeiras, 2013a). 
el propio Francisco en Caacupé (tal como desarrollamos en otro lugar, cfr. Carbonelli y Giménez Béliveau, 2016) y, como veremos a continuación, en próximos apartados, como elementos articuladores de la protesta socio-religiosa.

Las actividades en Constitución y Plaza Moreno fueron esporádicas. Se ejercitaron durante los primeros meses de la constitución del movimiento y luego dejaron de llevarse a cabo. En una charla que mantuvimos recientemente con uno de los máximos dirigentes de MMF dijo "y... tendríamos que volver a Constitución, era muy importante para nosotros" ¿Qué era lo importante? ¿Qué era lo que se ponía en juego allí? ¿de qué nos habla la discontinuidad y la añoranza? Nuestra primera hipótesis remitió a las características del territorio en cuestión, cuyas dinámicas y reglas constitutivas imponen condiciones. Plaza Constitución es un territorio difícil de marcar, inclusive para las organizaciones que disponen una expertise en las acciones orientadas al proselitismo. La dinámica incesante de personas que van de un lado al otro, guiados por intereses múltiples y prefijados, en una interacción ordenada o estructurada por el anonimato, impone límites y condiciona, al punto que demanda un gasto de energía renovado para fijar marcas y obtener reconocimiento en un terreno signado por la lógica de la rutina anónima. Más tarde complementamos la hipótesis con una segunda conjetura: para Misioneros, las misiones en Plaza Constitución y Moreno fueron en sus orígenes instancias de prueba, de sondeo y de producción que midieron sus saberes para difundir un mensaje religioso. Ensayaron la eficacia pública de tareas sencillas como repartir estampitas, convocar mediante un megáfono, poner una imagen conocida de manera estratégica, pedir oraciones. Algunos Misioneros pusieron a prueba sus saberes, otros aprendieron de los que tenían mayor experiencia e iban ajustando en el despliegue de la propia praxis sus discursos, sus maneras de acercarse y de invitar a los desconocidos

Las misiones prefiguraron, desde la perspectiva de la organización, una posibilidad valiosa para conocer de primera mano, a partir de la experiencia, la vigencia o el estado vital del catolicismo popular que era el objeto de búsqueda y recreación por parte del propio movimiento. En la proximidad, en la puesta en escena y despliegue de un conjunto de acciones clásicas dentro del repertorio católico de expansión territorial, los Misioneros exploraron y tantearon la vigencia de una religiosidad, dentro de sus cánones, criterios y expectativas. Si se tiene en cuenta el conjunto amplio de acciones que los misioneros 
desplegaron en el espacio público a partir de esos eventos iniciáticos, es posible advertir que partieron de la premisa de la existencia y vigencia de un sustrato católico en las prácticas religiosas populares: practicas dispersas, expresadas en los márgenes de la institución, pero vitales e intensas en su expresión.

Finalmente, si bien las actividades "de misión" que describimos en este apartado reúnen las características típicas de acciones pensadas "hacia afuera", orientadas a la publicidad manifiesta de darse a conocer y convocar, en el largo plazo de la vida del movimiento se revelaron analíticamente como instancias mucho mas productivas "hacia dentro", esto es, hacia el afianzamiento de los lazos entre los militantes, y en la producción de una identidad consolidada en una comunidad de saberes y expectativas. Cuando estas misiones se llevaron a cabo la mayoría de los Misioneros no se conocía entre si. Cada uno de los participantes provenían de sociabilidades anteriores reducidas y no necesariamente conexas: la militancia peronista en diferentes barrios, la participación en comunidades y parroquias de diferentes puntos del país. La puesta en prácticas de la misión y la posterior reflexión sobre las propias prácticas en comunidad resolvieron las disparidades de trayectorias y andamiaron el proceso de construcción del colectivo Misioneros de Francisco.

\section{El mapa, el territorio y sus distancias. El proyecto de las capillas de MMF}

La propuesta de Misioneros de Francisco parte de un diagnóstico sobre la crisis de las instituciones encargadas tradicionalmente de la gestión de las demandas de los sectores populares, que comparte con las organizaciones entre las que sus miembros circulan, el Movimiento Evita y la CTEP. Pese al crecimiento económico evidenciado durante la primera década del segundo milenio, persisten núcleos de población marginalizados, segmentados, separados violentamente de la trama social que el capitalismo construye y que son alcanzados de manera fragmentaria e incompleta por las políticas sociales del Estado, las redes políticas clientelares y las de asistencia religiosa (Kessler, 2014).

Para poder subsanar esta marginación MMF propuso desde sus orígenes armar un dispositivo como las capillas, independiente de las burocracias eclesiales y partidarias, y orientado a la integración con la vida asociativa de los 
sectores populares. Hasta el momento el Movimiento lleva construidas catorce capillas en barrios periféricos, asentamientos y villas del Gran Buenos Aires y otras zonas urbanas relegadas del interior del país.

$\mathrm{Al}$ igual que las actividades proselitistas que describíamos en el primer apartado, las dinámicas de las capillas de Misioneros de Francisco se inscriben en la cosmovisión propia de la teología del pueblo. Capillas que, si bien son edificadas por miembros de la organización, con el apoyo de organizaciones sindicales y movimientos sociales, sólo pueden ser dinamizadas por vecinos del barrio, a menudo por mujeres y hombres migrantes. En las capillas tienen lugar bautismos, responsos, casamientos, comuniones, rezos comunitarios, catequesis y la celebración de festividades religiosas populares y locales, estas últimas respetando las religiosidades más veneradas en el lugar.

Además de esta secuencia de prácticas religiosas, que se inscriben en el horizonte de un catolicismo de base, barrial, con una autonomía relativa respecto de las injerencias burocráticas (en las capillas de Misioneros se bautizan niños y niñas sin importar la condición marital de sus padres, por ejemplo) también tienen lugar actividades sociales orientadas a la inclusión: apoyo escolar, reuniones de vecinos para enfrentar problemáticas colectivas como la inseguridad o la falta de algún recurso básico, como la llegada de líneas de colectivos que conecten al barrio con las principales centros urbanos. En las capillas de Misioneros de Francisco tienen lugar inclusive la ejecución de ciertas políticas sociales implementadas por el estado nacional, provincial o municipal. ${ }^{5}$

Pero la dinámica política de las capillas trasciende las iniciativas en pos de la integración comunitaria y el abordaje integral de sus problemáticas. Estos dispositivos territoriales también se insertan en tramas que posicionan a los barrios como ejes de acción de lo político (Merklen, 2005). Varias capillas están emplazadas en territorios ocupados por sus pobladores, tras procesos conflictivos por el derecho de la vivienda. Tal es el caso de la capilla Negro Manuel, situada en un territorio ganado por militantes sociales, que originariamente dependía de la Arquidiócesis de Mercedes-Luján y que el Municipio reclamaba como propio. Erigir una capilla en dichas zonas "en litigio" remite a una acción

5 Diversas capillas de Misioneros fueron sede de los programas FINES y ENVIÓN, pensados para asistir a aquellos que aún no completaron sus estudios secundarios obligatorios. 
política orientada a legitimar y acompañar, nutrir la resistencia y de luchas por derechos en el largo plazo. La comunidad de Barrios Los Hornos (La Plata, provincia de Buenos Aires), está conformada estrictamente por mujeres víctimas de violencia de género, que para enfrentar su situación decidieron formar una comunidad, ocupar tierras y fundar una capilla que lleva por nombre el de Azucena Villaflor, una de las fundadoras de las Madres de Plaza de Mayo. La capilla de José C. Paz, en el conurbano bonaerense, surgió también del deseo de organización de los habitantes de un asentamiento en las que la llegada de los servicios básicos depende más de las acciones vecinales que de la intervención del estado en sus distintos niveles.

La diversidad de actividades que tienen lugar en la capilla visibiliza su condición liminar con respecto a dos grandes instituciones: el peronismo y la Iglesia católica. La relación con el peronismo resulta cuasi-natural, toda vez que un número importante de Misioneros provienen de espacios militantes peronistas, principalmente del Movimiento Evita. Esta doble pertenencia facilita la tracción de recursos hacia las capillas, como así también una comunidad de saberes prácticos, claves en el devenir de una acción territorial: "saber" organizar eventos públicos, marchas, comunicarse con los vecinos, atender y organizar sus demandas. En las filas de Misioneros, los que provienen del mundo político conviven con otros actores que provienen del campo católico, en sus variantes más progresistas y atentas a las demandas populares. Esta confluencia es la que nutre estas experiencias. La contracara de esta convergencia virtuosa resulta que ciertos conflictos, tensiones y coyunturas políticas mayores amenazan con irrumpir en las dinámicas pretendidamente autónomas de las capillas: cierre de listas electorales, agendas partidarias, entre otras. En por eso que en MMF hay una constante vigilancia para que las capillas no se conviertan en "unidades básicas", esto es, en ramificaciones territoriales de una estructura política formal. El antídoto contra esta amenaza -constante- resulta la búsqueda de la primacía de la agenda local.

En cuanto a la relación con la Iglesia Católica, las tensiones son más nítidas, porque las capillas representan unidades territoriales religiosas que no se encuentran incardinadas, esto es, subordinadas al poder diocesano de los obispos. Sus actividades religiosas no están estructuradas por las decisiones, las agendas y las prioridades de la jerarquía eclesial, aunque sí requieren -por pedido expreso de los vecinos y capilleros- la presencia de un sacerdote para 
los oficios religiosos. La singularidad de estas dinámicas de autonomía, que no prescinde a los especialistas, genera conflictos, ya que para la visión episcopal las capillas resultan zonas grises no asimilables a su planificación normativa.

Misioneros de Francisco cuenta con la bendición del papa, y representa un proyecto sui generis que reclama importantes porciones de autonomía respecto de la estructura jerárquica de la Iglesia católica. Como todas las fundaciones en los márgenes de la institución (Giménez Béliveau, 2016), su presencia en el territorio genera incomodidades: en la mirada de algunos obispos, la idea de promover capillas en sectores populares que se autogestionan, que predican una dinámica horizontal, estructurada en torno a las demandas del pueblo, resulta un desafío a su poder jurisdiccional.

Los obispos tienen a cargo las diócesis, dominios territoriales donde impera su gobierno: una línea pastoral, con horizontes, metas y acentos doctrinarios y litúrgicos distintivos y cercanos al perfil del propio obispo, una disposición de los especialistas religiosos (qué sacerdote es asignado a cada parroquia y según qué criterios) y finalmente, un arbitraje en ultima instancia de los conflictos que pudieran suceder en cualquier punto de su jurisdicción. En la perspectiva de un poder territorializado y cuasi-monárquico, los reclamos de gestión autónoma de la religiosidad son considerados disidencias más que oportunidades de profundizar la misión religiosa a partir de un enriquecimiento y heterogenización de las prácticas.

En el caso de las capillas de Misioneros, estas tensiones se materializan sobre todo en un orden micro: el caso más típico es la negativa de disponer de sacerdotes diocesanos para que participen de las celebraciones organizadas por los Misioneros. Entre los sacerdotes, que reproducen el poder territorial en una jurisdicción de menor rango, es frecuente la sospecha respecto de la manifiesta afiliación partidaria de los miembros de Misioneros de Francisco. Temen que la pastoral parroquial quede asociada a una adscripción política, y de esa manera particularice y faccionalice una acción que, desde su planteo, debe situarse en el plano universal (la Iglesia es de todos y para todos).

En la práctica cotidiana de las capillas estas tensiones se resuelven a través de acuerdos particularizados, capilla por capilla: en algunas se consigue que el sacerdote del lugar acepte presidir las celebraciones, en otras esa presencia se demora o nunca se concreta, lo que conduce a la suspensión de las demandas de sacramentos. 
Dos episodios ilustran las tensiones de las capillas con las instituciones político-estatales y eclesiásticas presentes en el territorio. El primero acontece en la capilla de Barrio La Nueva, ubicada en el oeste del conurbano bonaerense. Carlos y su hija Alma eran los animadores principales de la capilla: sus trayectorias representaban itinerarios biográficos típicos en la composición social de MMF. Carlos había sido un histórico militante de una de las fracciones peronistas de los setenta y si bien en la actualidad no participaba activamente en actividades políticas, su acervo de experiencias representaba su guía de acción permanente: además de su trabajo habitual, Carlos llevaba adelante una actividad social intensa, que se desplegaba en la organización de kermesses, colectas para personas necesitadas del barrio, y fundamentalmente, la organización del Día del Niño y de la festividad de los Reyes Magos, donde además de números y espectáculos infantiles, se organizaba una merienda colectiva y el célebre reparto de juguetes, que Carlos conseguía gracias a la confianza que se había ganado de comerciantes de la zona, pero también de algunos concejales del distrito. Hombre con profundas convicciones católicas, también participaba junto con su hija de las actividades de la parroquia barrial y en ocasiones había logrado armar actividades en conjunto. Y aunque su hija sí formaba parte de uno de los grupos parroquiales, sus emprendimientos eran más bien autónomos.

La participación de Carlos y de su hija en Misioneros de Francisco, sumado a los cambios del panorama político a escala nacional y municipal representaron los ejes dinamizadores de un conflicto con el párroco de la zona. Carlos y Alma nos contaron que desde un principio el cura desconfió de la capilla de Misioneros, porque era una actividad "que no era lo que el obispo quería" y porque lo veía como algo "muy político". En realidad, lo que distanciaba al párroco de los Misioneros en cuestión era, según su relato, una diferencia política: mientras que los Misioneros reivindicaban sus afiliaciones simbólicas con el peronismo y lo expresaban en cada uno de sus eventos, el referente católico se sentía más a gusto con el nuevo intendente, del sello político de Cambiemos, que había desplazado al histórico intendente peronista de La Nueva. Las tensiones se pusieron de manifiesto rápidamente bajo una modalidad territorial. El nuevo intendente promovió reformas en la plaza vecinal, que incluían la remoción de una imagen de la Virgen del Rosario en la plaza. El párroco decidió no intervenir en la decisión del funcionario y su omisión despertó el enojo 
de Carlos y de su hija, que alertaron a sus vecinos, pero también a sus compañeros de militancia de Misioneros para impedir el desplazamiento de la imagen, lo que significaba para ellos un ultraje. Finalmente, la virgen no se movilizó de la plaza, merced a las alianzas orquestadas por los referentes misioneros, quienes terminaron redoblando la apuesta: su paso siguiente de acción en el barrio fue pintar un mural del Papa Francisco a lo largo y a lo ancho de un viejo paredón, que se remataba con la leyenda Tierra Techo y Trabajo.

El segundo episodio tuvo lugar en una capilla fundada en el centro de un asentamiento en el segundo cordón del gran Buenos Aires. Creado en tierras usurpadas que pertenecían a una empresa, el asentamiento nació marcado por una territorialidad escindida: de un lado del riacho se instalaron grupos migrantes provenientes en su mayoría de Paraguay y Bolivia, del otro argentinos. El "lado migrante" del asentamiento prosperó: con la asistencia de grupos políticos, entre ellos una sección del Movimiento Evita, se realizó un campo de juegos, se proyectó el jardín maternal y se levantó la capilla. La capilla estuvo desde sus orígenes atravesada por territorialidades diferenciadas, y por disputas entre los grupos en torno de la maneras de gestionarla. La capilla se construyó con los aportes del estado (nacional, provincial y municipal) que proveyó materiales los materiales de construcción, y de los habitantes del barrio, que la levantaron con su trabajo.

La inauguración de la capilla puso en escena la compleja trama institucional en la que se insertan los Misioneros: una procesión que comenzó en la parroquia y terminó en la capilla atravesó el barrio el día de la ceremonia. La procesión estaba encabezada por una imagen de la Virgen de Caacupé, seguida por integrantes de Misioneros de Francisco y del Movimiento Evita, con sus respectivas banderas. La presencia manifiesta de las adscripciones políticas hizo que el sacerdote de la parroquia no acompañara la procesión, aunque sí ofició misa en la capilla, más tarde. Cuando la procesión se acercó a la capilla, salió a su encuentro una comitiva en sentido contrario encabezada por niños que llevaban imágenes de la virgen de Luján y las banderas paraguaya, peruana y argentina.

El cartel que ilustraba las vicisitudes de la construcción de la capilla, desde la delimitación del terreno hasta la inauguración de la misma en octubre de 2015, concluía afirmando que "Hoy son los vecinos, la Comisión Vecinal y la JP Evita quienes, junto a Misioneros de Francisco, concretan un sueño. Que esta 
capilla sea el símbolo de que cuando estamos unidos nada es imposible". ${ }^{6} \mathrm{El}$ sueño de la unidad duró, sin embargo, poco: la Comisión Vecinal, compuesta por los habitantes del barrio, terminó apropiándose de la capilla y distanciándose del Movimiento Evita, a quienes consideraban excesivamente politizados, y afirmando sus relaciones con actores de la pastoral diocesana, delegados directos del entrono del obispo. El sacerdote de la parroquia más cercana espació sus visitas a la capilla, como lo hicieron también los Misioneros. Las múltiples institucionalidades eclesiásticas -parroquia, pastoral diocesana, Misioneros de Francisco- y políticas -Movimiento Evita, Comisión Vecinalcontribuyeron al surgimiento de la capilla en el asentamiento pero no lograron establecer acuerdos permanentes de convivencia: la permanencia de Misioneros en esa capilla se vio seriamente comprometida.

En suma, las tensiones y arreglos que se suscitan en las capillas ponen en escena los roces y las difíciles complementariedades entre diferentes dispositivos territoriales, pre-existentes a la llegada de los Misioneros y competidores parciales de su programa, puntualmente las parroquias católicas y los municipios. Ambos dispositivos ameritan ser pensados como proyectos territoriales incompletos, permanentemente desbordados por la complejidad de un territorio en continua mutación. Las parroquias católicas no consiguen garantizar el monopolio el espacio de la oferta de los bienes de salvación, desafiadas y desplazadas por nuevas formas de creer y por la propia indiferencia religiosa. En lo que concierne a la demanda, se encuentran interpeladas por problemáticas situadas por fuera de las interacciones exclusivamente rituales entre creyentes y especialistas: los fieles reclaman escucha, ayuda para resolver problemas personales, familiares y laborales complejos, sostén frente a malestares cuya respuesta no encuentran (Giménez Béliveau, 2017; Martins, 2016).

En el caso de los municipios, el panorama no varía, aun cuando se trate de un terreno donde circulan bienes materiales y simbólicos de distinta índole. Los municipios dependen de fondos provinciales y nacionales en la mayoría de sus actividades de gestión y esta dependencia acentúa la inestabilidad de su presencia en el territorio, a lo que se suma el desafío a su control provenientes de las formas encadenadas de violencia (Auyero; Berti, 2013) y la proliferación

6 Registro de campo, 11 de octubre de 2015. 
de economías legales y/o ilegales (Rodríguez Alzueta, 2004), por solo mencionar dos fenómenos que desafían la autoridad legal del Estado. Frente a estos desafíos no resueltos y la disparidad entre los mapas institucionales y las dinámicas "reales" del territorio, la presencia de un nuevo actor como las capillas de los misioneros fue leída, hasta el momento, más en clave competitiva que de alianza. En otras palabras: a la luz de las problemáticas desgastantes e irresueltas que afrontan en su gestión cotidiana parroquias y municipios, las capillas fueron conceptualizadas como un elemento intrusivo, ilegible y amenazante, en gran parte porque venia a poner en evidencia el carácter incompleto e insuficiente de su gestión.

\section{De San Cayetano a Plaza de mayo. La religión en clave beligerante}

Misioneros de Francisco despliega su presencia en el espacio público a través de múltiples iniciativas. Como vimos, la realización de capillas católicas constituye una de sus apuestas principales, la otra es organización y acompañamiento de peregrinaciones y manifestaciones masivas.

Desde el comienzo los Misioneros de Francisco decidieron participar regularmente de las celebraciones de San Cayetano: consideran al Santo uno de los representantes de la religiosidad popular de la que ellos mismos debían nutrirse en su acción político-religiosa ordinaria. San Cayetano es una de las devociones religiosas católicas más populares de la Argentina. Conocido como el Santo patrono del Pan y del Trabajo, todos los siete de agosto su santuario se colma de peregrinos y devotos, que le ruegan y le agradecen su protección (Giménez Béliveau; Carbonelli, 2017).

El 7 de agosto de 2016, los Misioneros decidieron imprimir un carácter distinto a la tradicional celebración. Se trataba de la primera fiesta de San Cayetano bajo un signo político distinto al que ellos habían sostenido durante los últimos 12 años. Misioneros convocó a otras fuerzas sindicales, agrupaciones de izquierda y a los sectores agrupados en la CTEP para marchar juntos desde el santuario hasta Plaza de Mayo. El objetivo era reclamar por la sanción de una ley de Emergencia Social que garantizara un ingreso mínimo a los sectores más excluidos de la sociedad argentina. Una peregrinación religiosa cobraba así 
el sentido de una movilización política, desafiante, beligerante, inscripta decididamente en el plano de la protesta.

Para la ocasión, la marcha retomó un viejo lema. En el año 1981, la resistencia a la dictadura militar (1976-1983) retomaba su iniciativa, y "Paz, pan y trabajo" fue la consigna de una de las primeras convocatorias masivas organizadas por el dirigente sindical Saul Ubaldini. En aquel entonces la proclama desafiaba el poder de la dictadura y presagiaba su final. En un giro temporal, la marcha organizada por los Misioneros recuperó toda la potencialidad política del lema, para encolumnar a la disidencia política en torno a un reclamo. A la histórica Paz, Pan y Trabajo se sobreimprimió una segunda consigna, de clara raigambre francisquista: Tierra, Techo y Trabajo.

Como otros eventos políticos, la marcha adquirió un carácter altamente ritualizado: partió de Liniers, barrio periférico de la ciudad de Buenos Aires, fronterizo con el conurbano y asociado históricamente a la cultura obrera e inmigrante, para llegar a la Plaza de Mayo, epicentro político de la historia argentina. El recorrido sigue una de las principales arterias de la ciudad, la Avenida Rivadavia, que la atraviesae de oeste a este, marcando la división entre el norte de la ciudad, de arquitectura aristocrática y europeizante, del sur más pobre, postergado, siempre peligroso en el imaginario colectivo hegemónico. Marchar por esa vía implicó mostrar /mostrarse antes diferentes públicos, palpar y medir sus grados de aceptación y de rechazo.

Durante las casi cuatro horas de caminata, las consignas políticas y los canticos propios de las convocatorias militantes dominaron la escena, mientras banderas con inscripciones maoístas y guevaristas se confundían con imágenes del Sagrado Corazón de Jesús, Eva Perón y Vírgenes de Lujan. Los Misioneros presidían toda la columna (que aproximadamente reunió cien mil personas durante diez kilómetros) portando tres íconos: una imagen de la Virgen de Luján, patrona de la Argentina, otra de San Cayetano, como dijimos, santo popularísimo por su ligazón con la cuestión laboral y un estandarte del Papa.

Los Misioneros recibieron el acompañamiento de vecinos auto-convocados que saludaban su paso agitando banderas argentinas o aplaudiendo. Inquilinos y propietarios los aplaudían o simplemente los miraban desde los balcones de los edificios que se agolpaban a medida que se acercaban al centro de la ciudad. En su caminar los Misioneros y sus aliados también conocieron 
la hostilidad de los bares que cerraban sus puertas, y de vecinos que los hostigaban desde los balcones.

El cierre de la movilización en Plaza de Mayo mantuvo la tesitura político-religiosa bajo la cual había sido configurada. Según los usos y estilos de la tradición política argentina, los referentes de las diferentes organizaciones ocuparon el escenario dispuesto y desde allí enarbolaron discursos críticos a la política económica imperante y volvieron a remarcar el apoyo papal. Incluso se mencionó que Juan Carlos Alderete, referente de Barrios de Pie (una de las columnas más numerosas de la manifestación), había sido recibido por su Santidad en Roma y que, desde su sede pontificia, se bendecía la protesta por su carácter justo. Tras las alocuciones políticas, los aplausos y las últimas arengas, el clima se tornó decididamente festivo: algunos grupos musicales folclóricos ocuparon el escenario y amenizaron el ambiente, mientras los presentes comían alimentos típicos como el locro o el choripán.

La movilización tuvo una amplia repercusión mediática: la masividad y el hecho de constituirse de una de las primeras acciones públicas opositoras al nuevo gobierno, le valieron las portadas de los principales matutinos del lunes 8 de agosto. En términos políticos, las consecuencias también fueron exitosas: la presión surtió efecto e impidió que se desmantelara toda una red de políticas de asistencia social, forjadas durante el gobierno previo, y vitales en la garantía de recursos básicos por parte de los sectores más castigados por el ajuste. También consiguió la sanción de una ley de Emergencia social por parte del gobierno de Mauricio Macri. Finalmente, la movilización por Paz Pan y Trabajo cumplió ampliamente su propuesta performativa de afianzar la figura de Francisco como uno de los estandartes de la resistencia social al ajuste y a la desposesión colectiva.

La asociación de símbolos religiosos profundamente arraigados en la cultura popular argentina -la Virgen, San Cayetano, y la figura icónica de Francisco se reveló como una potente apuesta para unificar espacios opositores de diversos orígenes políticos y sociales. En 2017 se repitió la marcha, con una apuesta política redoblada: no sólo se reclama el cumplimiento efectivo de la ley de Emergencia Social, sino la profundización de la asistencia a sectores populares a través de una ley de Emergencia alimentaria.

La figura del papa funciona a la vez como ícono y como potenciador de las causas sostenidas por los movimientos sociales: las articula en un mismo relato, des-particularizándolas, asociándolas entre sí y ligándolas a una problemática 
global. En el giro geopolítico de su Iglesia, Francisco pareciera decirle al auditorio mundial:

Todas esas problemáticas que conocemos: las expulsiones en el mercado laboral, la marginalidad, los problemas de tierra de los campesinos, la inmigración que no encuentra cobijo, no son conflictos desunidos, reducibles a sus contextos de origen. Todos y cada uno de ellos remiten a una única causa que aquí denuncio: la fase actual del capitalismo financiero, la lógica perversa que se reproduce gracias a y a costa de la exclusión de millones.

Está claro que no es el primero que produce esta articulación discursiva, pero sí que resulta uno de los pocos que se revela capaz de captar a los públicos más diversos. El recurso al Francisco-símbolo en el espacio público se revela así una performance sumamente eficaz: congrega y aglutina actores de proveniencias diversas, magnifica los discursos protestatarios y los inscribe en un escenario público global.

\section{Conclusiones}

En este artículo nos propusimos, a través del abordaje etnográfico de Misioneros de Francisco, analizar las principales modalidades de intervención pública de un movimiento situado deliberadamente en la intersección de los espacios políticos y religiosos, fuertemente referenciado en la figura emblemática del papa argentino, y cuya praxis reviste un carácter eminentemente territorial.

En nuestro seguimiento del movimiento, encontramos tres espacios decisivos donde la propuesta de Misioneros de Francisco se puso en escena: las plazas como espacio misional, las capillas como punto de interacción con las instituciones y prácticas de la politicidad y religiosidad popular, y la calle como ámbito de protesta.

Luego de un período de ensayo de la acción pública en que se probaron los alcances y las potencialidades de la intervención en estaciones de trenes y plazas, el Movimiento definió sus formas centrales de acción: la fundación de capillas y las manifestaciones y peregrinaciones. En estas primeras proyecciones, el grupo se apropió de un territorio texturado, y se probó. La reflexión sobre 
las prácticas de las "salidas" de los primeros tiempos los preparó para consolidar y delinear las estrategias que se volverán luego las modalidades prioritarias de acción: la dinámica de la circulación permanente y de interacciones anónimas moduló el hacer misionero, al punto de transformar la misión en una instancia de sondeo, prueba y construcción identitaria. La eficacia de esta práctica se midió más en función de la posibilidad de vigorizar hacia dentro los lazos iniciáticos del movimiento, en términos de fusión de saberes y creencias.

La fundación de capillas se montó sobre el imaginario de control del territorio típico de instituciones como la Iglesia y el Estado: instalarse en el territorio suponía hacerse con ese objeto de deseo heredado de la doble tradición religiosa y política, "el pueblo", en sus lugares de vida cotidiana. Pero instalarse en el territorio de manera permanente encontró tensiones con las instituciones múltiples que lo habitan: la trama social de las capillas fue la que desnudó un mayor numero de resistencias e interrogantes para una propuesta mixta como la de Misioneros. Las tensiones se multiplicaron en la vida cotidiana de las capillas: con las instituciones políticas -partidos políticos, movimientos y los niveles municipal, provincial y nacional del estado-y las distintas institucionalidades y agencias de la iglesia católica-los párrocos, los movimientos, los obispos.

Por otro lado, el "pueblo católico", que está en la base del proyecto de las capillas, no siempre se corresponde exactamente con el que los Misioneros imaginaban. El "catolicismo popular" no sólo convive en territorios heterogéneos con otras pertenencias y creencias religiosas, espirituales y políticas, sino que no siempre elige el espacio local para expresar la fe. Los creyentes católicos con mayor o menor cercanía a la Iglesia a los que Misioneros quieren llegar no inscriben necesariamente sus prácticas religiosas/ políticas en el territorio de la manera cotidiana y regular que la fundación de las capillas supone.

En lo que respecta al espacio de la calle, la tradiciones políticas y religiosas previas en términos de movilización en Argentina facilitaron el armado de una acción disruptiva, sin determinarla. Lo que está en juego en las movilizaciones y peregrinaciones masivas que organiza y a las que adscribe Misioneros, como las marchas del 7 de agosto de 2016 y 2017, es la capacidad de los símbolos y figuras religiosas para articular la dispersión política del campo popular, luego de su crisis hegemónica en las elecciones presidenciales 2015. La masividad de estos encuentros y la claridad de los reclamos visibilizó la potencia de estos elementos y la renovación activa de las tradiciones. 
Como ha señalado Segato (2007) la retracción del Estado en las tareas de organización y cobertura de dimensiones vitales de la vida comunitaria e individual (salubridad, seguridad, educación, acceso a bienes simbólicos y culturales) abrió el paso a la gravitación de agencias que, a escala territorial, disputan poder entre sí. Auténticas facciones que intentan abrirse paso y monopolizar el control de los espacios y someter, por la seducción o por las fuerzas, a las poblaciones que allí se encuentran.

Y así como en el proyecto de instalación en el territorio aparecen tensiones que hacen peligrar su crecimiento, en el proyecto de tránsito por el espacio público los símbolos religiosos cargados de significación política que los Misioneros portan cumplen cabalmente su objetivo: significan, dicen hacia fuera del grupo, y consolidan identificaciones hacia adentro. Las manifestaciones y peregrinaciones constituyen, además, prácticas que reconocen afinidades con el tipo de religiosidad imperante en la sociedad contemporánea, marcada más por la prácticas extraordinarias y extracotidianas de los "altos lugares y momentos fuertes" (Hervieu-Léger, 1999) que por las observancias regulares. El caminar ilumina, atrae, aparece como un momento que será relatado y recordado, que abrirá a su vez nuevas instancias de profundización del compromiso: permite también reafirmar comunitariamente las pertenencias y constatar el reconocimiento que el tránsito por el espacio público tiene: los medios masivos de comunicación y sitios web reafirman la idea del éxito publicando las manifestaciones como hechos destacados. Tales hechos extraordinarios no alcanzan, sin embargo, para perpetuar la existencia del Movimiento, que necesita del compromiso cotidiano en espacios barriales para garantizar su continuidad. Las formas diferentes de habitar en el espacio público son una apuesta en este sentido.

\section{Referencias}

ALGRANTI, J. Episodios religiosos: exploraciones sobre la inespecificidad del carisma. Miríada: Investigación en Ciencias Sociales, Buenos Aires, año 6, n. 10, p. 61-88, 2014.

AMEIGEIRAS, A. Culture populaire et religion: approches théoriques de la religiosité populaire au sein des cultures populaires latino-américaines. Social Compass, Louvain, v. 55, n. 3, p. 304-315, 2008. 
AMEIGEIRAS, A. Iglesia Católica y modernidad contemporánea. Una mirada desde Latinoamérica. Estudos de Religião, São Paulo, v. 27, n. 2, p. 159-176, $2013 \mathrm{a}$.

AMEIGEIRAS, A. Pueblo Santo o Pueblo Justo. Alternativas teológico-pastorales en una diócesis del Gran Buenos Aires. In: JUDD, E.; MALLIMACI, F. (Coord.). Cristianismos en América Latina: tiempo presente, historias y memorias. Buenos Aires: CLACSO, 2013b. p. 195-222.

AUYERO, J.; BERTI, M. F. La violencia en los márgenes: una maestra y un sociólogo en el conurbano bonaerense. Buenos Aires: Katz, 2013.

BERGER P.; LUCKMANN T. La construcción social de la realidad. Amorrortu: Buenos Aires, 1989.

BLANCARTE, R. Laicidad y secularización en México. Estudios Sociológicos, México D.F., v. 19, n. 57, p. 843-855, sept./dic., 2001.

BLANCARTE, R. Laicidad y laicismo en América Latina. Estudios Sociológicos, México D.F., v. 26, n. 76, p. 139-164, enero/abr. 2008.

CARBALLO, C. T. Peregrinos católicos y religiosidad popular en Argentina. Estudios Socioterritoriales: Revista de Geografía, v. 8, n. 1, p. 53-69, 2010.

CARBONELLI, M. A. Los evangélicos en la arena política del conurbano. Dilemas y horizontes de una apuesta religiosa territorial. Mitológicas, Buenos Aires, v. 29, p. 41-64, 2014.

CARBONELLI, M. A; GIMÉNEZ BÉLIVEAU, V. Misioneros de Francisco en Caacupé. El viaje y los objetos de culto a través de la etnografía de una peregrinación político religiosa. Debates do Ner, Porto Alegre, ano 17, n. 29, p. 329-359, 2016.

CARBONELLI, M. A.; MOSQUEIRA, M. A.; FELITTI, K. Religión, sexualidad y política en la Argentina: intervenciones católicas y evangélicas entorno al aborto y el matrimonio igualitario. Revista del Centro de Investigación, v. 9, n. 36, p. 25-43, jul./dic. 2011.

CARNEIRO, S. de S. O caminho do sol: construindo emoções, ethos peregrino e vínculos sociais. In: STEIL, C. A.; CARNEIRO, S. de S. (Org.). Caminhos de Santiago no Brasil. Rio de Janeiro: Faperj: Contra Capa, 2011. p. 75-107.

CEFAÏ, D. Qu'est-ce qu'une arène publique? Quelques pistes pour une approche pragmatiste. In: CEFAÏ, D.; JOSEPH, I. (Dir.). L’héritage du pragmatisme: conflits d'urbanité et épreuves de civisme. Paris: La Tour d’Aigues: L’Aube, 2002. p. 76-102.

CEVA, M. Inmigración y iglesia. Las peregrinaciones extranjeras a Lujan hacia el centenario. In: FOGELMAN, P.; CEVA, M.; TOURIS, C. (Ed.). El culto mariano en Lujány San Nicolás: religiosidad e historia regional. Buenos Aires: Biblos, 2013. p. 51-66. 
DA COSTA, N. La laicidad uruguaya. Archives de Sciences Sociales des Religions, Paris, n. 146, p. 137-156, 2009.

ESQUIVEL, J. C. Cultura política y poder eclesiástico: encrucijadas para la construcción del Estado laico en Argentina. Archives de Sciences Sociales des Religions, Paris, n. 146, p. 41-59, 2009.

ESQUIVEL, J. C. Catolicismo y modernidad en Argentina: ¿de la confrontación a la conciliación?. Estudos de Religião, São Paulo, v. 27, n. 2, p. 193-213, 2013 a.

ESQUIVEL, J. C. La carrera por un Papa Propio. Le Monde Diplomatique, Buenos Aires, n. 166, 2013b. Disponible en: <https://www.eldiplo.org/166-de-chavez-a-francisco/ la-carrera-por-un-papa-propio/>. Acceso: 30 ago. 2017.

FEDIAKOVA, E. Saliendo del "refugio de las masas": evangélicos chilenos y compromiso social (1990-2010). In: PARKER GUMUCIO, C. Religión, política y cultura en América Latina: nuevas miradas. Santiago de Chile: Instituto de Estudios Avanzados: USACH/ACSRM, 2012. p. 125-145.

FLORES, F. San Nicolás, entre el acero y las promesas. In: FOGELMAN, P.; CEVA, M.; TOURIS, C. (Ed.). El culto mariano en Luján y San Nicolás: religiosidad e historia regional. Buenos Aires: Biblos, 2013. p. 119-141.

FRESTON, P. Evangélicos na política brasileira: história ambígua e desafio ético. Curitiba: Encontrão, 1994.

FRIGERIO A.; RENOLD, J. M. (Comp.). Visiones del Papa Francisco desde las Ciencias Sociales. Rosario: UNR, 2015.

GIMÉNEZ BÉLIVEAU, V. Del barrio a la cima del mundo. Revista Anfibia, marzo 2013. Disponible en: <http://www.revistaanfibia.com/ensayo/francisco-delbarrio-la-cima-del-mundo/>. Acceso: 30 ago. 2017.

GIMÉNEZ BÉLIVEAU, V. Francisco. Escalas y politicidades de la relación del papa con los latinoamericanos. Revista Caminos, La Habana, n. 76-77, p. 4-14, 2015.

GIMÉNEZ BÉLIVEAU, V. Católicos militantes: sujeto, comunidad e institución en Argentina. Buenos Aires: Eudeba, 2016.

GIMÉNEZ BÉLIVEAU, V. Terapéuticas católicas, males modernos. Procesos de sanación y exorcismo en la Argentina. Sociedady Religión, v. 47, p. 33-59, 2017.

GIMÉNEZ BÉLIVEAU, V.; CARBONELLI, M. A. Movilización política, memoria y simbología religiosa: San Cayetano y los movimientos sociales en Argentina. Revista Latinoamericana de Investigación Crítica, n. 6, p. 51-70, 2017. 
GIMÉNEZ BÉLIVEAU, V.; MARTÍNEZ, A. T. Símbolos religiosos en el espacio urbano. In: MALLIMACI, F. Atlas de las creencias religiosas en la Argentina. Buenos Aires: Biblos, 2013. p. 217-220.

GIUMBELLI, E. Símbolos religiosos em controvérsias. São Paulo: Terceiro Nome, 2014. GUTIÉRREZ ZÚÑIGA, C. La danza neo-tradicionalista como oferta espiritual en la estantería exotérica New-Age. In: ARGYRIADIS, K. et al. Raíces en movimiento: prácticas religiosas tradicionales en contextos trans-locales. Zapopán: El Colégio de Jalisco: CIESAS: IRD: CEMS, 2008. p. 363-392.

GUTIÉRREZ ZÚÑIGA, C.; DE LA TORRE, R.; CASTRO, C. Una ciudad donde habitan muchos dioses: cartografía religiosa de Guadalajara. Zapopán: CIESAS: El Colegio de Jalisco, 2011.

HERVIEU-LÉGER, D. Le pèlerin et le converti: la religion en mouvement. Paris: Flammarion, 1999.

JONES, D.; VAGGIONE, J. M. Los vínculos entre religión y política a la luz del debate sobre matrimonio para parejas del mismo sexo en Argentina. Civitas: Revista de Ciências Sociais, Porto Alegre, v. 12, n. 3, p. 522-537, jan. 2013.

KESSLER, G. Controversias sobre la desigualdad Argentina, 2003-2013. Buenos Aires: Fondo de Cultura Económica, 2014.

MACHADO, M. D. C. et al. La política: un nuevo espacio de articulación de las identidades religiosas y de género. Si Somos Americanos: Revista de Estudios Transfronterizos, v. 8, n. 2, p. 87-108, 2006.

MALLIMACI, F. Política y Catolicismo en el Gobierno del Dr. Kirchner: recomposición y disputa del poder simbólico. In: PARKER GUMUCIO, C. Religión, política y cultura en América Latina: nuevas miradas. Santiago de Chile: Instituto de Estudios Avanzados: USACH/ACSRM, 2012. p. 169-197.

MALLIMACI, F. Papa Francisco: entre la modernidad católica y la recomposición religiosa. Cuadernos del Pensamiento Crítico Latinoamericano, Buenos Aires, n. 1, p. 2-4, 2013a.

MALLIMACI, F. Crisis del catolicismo y un nuevo papado. Estudos de Religião, v. 27, n. 2, p. 270-296, 2013b.

MALLIMACI, F.; ESQUIVEL, J. C. Catolicismo, política y sociedad en el Bicentenario de la Argentina. Revista Argentina de Ciencia Política, Buenos Aires, n. 13-14, p. 127-146, 2011. 
MARCUS, G. Ethnography in/of the world system: the emergence of multi-sited ethnography. Annual Review of Anthropology, v. 24, p. 95-117, 1995.

MARTINS, I. R. Moralidades e atos de fala em serviços de apoio emocional: modalidades laicas da confissão e do testemunho?. Religião e Sociedade, Rio de Janeiro, v. 36, n. 2, p. 19-43, 2016.

MAUES, H. A Mãe e o Filho como peregrinos: dois modelos de peregrinação católica no Brasil. Religião e Sociedade, Rio de Janeiro, v. 33, n. 2, p. 121-140, 2013.

MERKLEN, D. Pobres ciudadanos: las clases populares en la era democrática [Argentina, 1983-2003]. Buenos Aires: Gorla, 2005.

NATALUCCI, A. Los movimentistas. Expectativas y desafíos del Movimiento Evita en el espacio kirchnerista (2003-2010). In: PÉREZ, G.; NATALUCCI, A. (Ed.). Vamos las bandas: organizaciones y militancia kirchnerista. Buenos Aires: Nueva Trilce, 2012. p. 27-53.

ORO, A. P. A política da Igreja Universal e seus reflexos nos campos religioso e político brasileiros. Revista Brasileira de Ciências Sociais, v. 18, n. 53, p. 53-69, out. 2003.

ORO, A. P. A laicidade no Brasil e no Ocidente. Algumas considerações. Civitas: Revista de Ciências Sociais, Porto Alegre, v. 11, n. 2, p. 221-237, maio/ago. 2011.

PRIETO, S. El fin del mundo: el fenómeno del Papa Francisco desde la sociología. Villa María: Eduvim, 2016.

RODRÍGUEZ ALZUETA, E. La violenta regulación del territorio en el capitalismo criminal. In: WACQUANT, L. et al. Tiempos violentos: barbarie y decadencia civilizatoria. Buenos Aires: Herramienta, 2004. p. 17-43.

SEGATO, R. L. La nación y sus otros: raza, etnicidad y diversidad religiosa en los tiempos de políticas de la identidad. Buenos Aires: Prometeo, 2007.

SEMÁN, P. El Pentecostalismo y la religiosidad de los sectores populares. In: SVAMPA, M. (Comp.). Desde abajo: la transformación de las identidades sociales. Buenos Aires: Biblos, 2000. p. 155-180.

SOCIEDAD Y RELIGIÓN. Buenos Aires, v. 23, n. 40, jul./oct. 2013.

STEIL, C. A.; MARQUES, B. R. O Caminho das Missões: reflexões antropológicas sobre uma experiencia de peregrinação contemporânea. In: STEIL, C. A.; CARNEIRO, S. de S. (Org.). Caminhos de Santiago no Brasil. Rio de Janeiro: Faperj: Contra Capa, 2011. p. 23-56. 
SUÁREZ, H. J. Ver y creer: ensayo de sociología visual en la colonia El Ajusco. Nezahualcoyotl: UAM: Quinta Chilla, 2012.

SUED, G. Misioneros de Francisco: capillas en las villas donde conviven política y religión. La Nación, 3 ago. 2014. Disponible en: <http://www.lanacion.com.ar/1715373misioneros-de-francisco-capillas-en-las-villas-donde-conviven-politica-y-religion>. Acceso: 30 ago. 2017.

TADVALD, M. A reinvenção do conservadorismo: os evangélicos e as eleições federais de 2014. Debates do NER, Porto Alegre, ano 16, n. 27, p. 259-288, jan./jun. 2015.

TOURIS, C. Catolicismo popular e imaginario liberacionista en los años '70. El caso de las peregrinaciones villeras a Luján y del Movimiento Villero Peronista. In: FOGELMAN, P.; CEVA, M.; TOURIS, C. (Ed.). El culto mariano en Luján y San Nicolás: religiosidad e historia regional. Buenos Aires: Biblos, 2013. p. 67-97.

ZAPPONI, E. Pregare con i piedi: in camino verso Finis Terrae. Roma: Bulzoni, 2008.

ZAPPONI, E. Marcher vers Compostelle: ethnographie d'une pratique pèlerine. Paris: L'Harmattan, 2011.

Recebido: 30/09/2017 Aceito: 11/05/2018 | Received: 9/30/2017 Accepted: 5/11/2018 